\title{
Francesca Billiani speaks to Gisèle Sapiro:
}

DOI:

$10.1080 / 13556509.2014 .968324$

Link to publication record in Manchester Research Explorer

\section{Citation for published version (APA):}

Billiani, F. (2014). Francesca Billiani speaks to Gisèle Sapiro: translating sociology. The Translator, 20(2), 229-242. https://doi.org/10.1080/13556509.2014.968324

\section{Published in:}

The Translator

\section{Citing this paper}

Please note that where the full-text provided on Manchester Research Explorer is the Author Accepted Manuscript or Proof version this may differ from the final Published version. If citing, it is advised that you check and use the publisher's definitive version.

\section{General rights}

Copyright and moral rights for the publications made accessible in the Research Explorer are retained by the authors and/or other copyright owners and it is a condition of accessing publications that users recognise and abide by the legal requirements associated with these rights.

\section{Takedown policy}

If you believe that this document breaches copyright please refer to the University of Manchester's Takedown Procedures [http://man.ac.uk/04Y6Bo] or contact uml.scholarlycommunications@manchester.ac.uk providing relevant details, so we can investigate your claim.

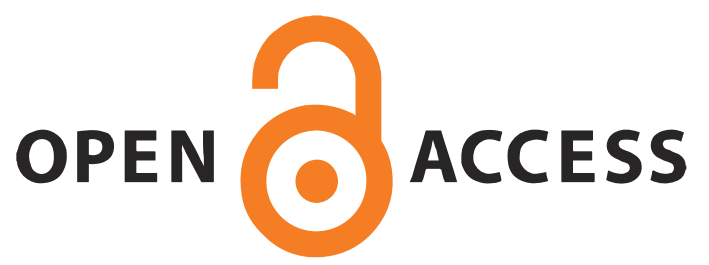




\section{Francesca Billiani speaks to Gisèle Sapiro: translating sociology}

\section{Francesca Billiani}

To cite this article: Francesca Billiani (2014) Francesca Billiani speaks to Gisèle Sapiro: translating sociology, The Translator, 20:2, 229-242, DOI: 10.1080/13556509.2014.968324

To link to this article: http://dx.doi.org/10.1080/13556509.2014.968324

曲 Published online: 24 Oct 2014.

Submit your article to this journal $\asymp$

LIII Article views: 234

Q View related articles ¿

View Crossmark data ¿ 


\section{Francesca Billiani speaks to Gisèle Sapiro: translating sociology}

Gisèle Sapiro is Professor of sociology at the Ecole des hautes études en sciences sociales and research director at the Centre national de la recherche scientifique (CNRS) in Paris, France. She specialises in the sociology of translation and of intellectuals, as well as in the sociology of literature, an area to which she devoted her most recent book, La Sociologie de la Littérature (Sapiro 2014a). In her first book, published in 1999 and recently translated into English, The French Writers' War, 1940-1953 (Sapiro 2014b), she drew on Bourdieu's field theory to analyse French writers' political choices during the German occupation. Focusing on literary trials, her second major book, La Responsabilité de l'Ecrivain. Littérature, Droit et Morale en France, XIXe-XXe siècles (Sapiro 2011) traces the processes through which writers' and intellectuals' struggles for freedom of speech and the autonomy of the arts in France freed the literary field from the State's control. She has also edited several books on translation, building a theoretical and methodological framework for the study of the international circulation of literary works and of the world market of translation: Translatio (Sapiro 2008b); Les Contradictions de la Globalisation Editoriale (Sapiro et al. 2009); L'Espace Intellectuel en Europe (Sapiro 2009); Traduire la Littérature et les Sciences Humaines (Sapiro 2012b); Sciences Humaines en Traduction Sapiro 2014c, Institut français/Centre européen de sociologie et de science politique [CESSP]).

In this conversation, the main issues addressed are the relationship between sociology and translation, the application of sociological methods to the study of translation (and vice versa), the relationship between the history and the sociology of translations, and the connections between translation and publishers, the book market, globalization, national identity and gender.

Francesca Billiani: You are a well-known sociologist, but we are here to talk about translation and translation studies. How do you see the connection between these two disciplines: as a natural transition to and from areas which are already connected and have something to share, or as 'coincidence'? More to the point, perhaps, is there something in your understanding of sociology that has made you gravitate towards translation studies?

Gisèle Sapiro: I was trained both in comparative literature and in translation studies, so for me the move was not a real move; rather it meant that I did return to where I had originally started from. Having said that, I was not alone in making this transition. In the 1990s, the interest in this topic had noticeably started to emerge in the social sciences in France: Pierre Bourdieu and Joseph Jurt began a project about the international circulation of ideas, for instance; and, during the same period, I had also been a translator from and 
into Hebrew. In many ways, and despite being familiar with the work involved in translating, I saw translation primarily as a practice, rather than as a topic to be approached analytically. As time passed, however, for me it did turn into a subject very much worth investigating scientifically. In 1999, my colleague, Johan Heilbron, wrote a seminal paper on the world system of translations, and since then we have been working together on issues concerning the international circulation of books and publishing strategies in and around Bourdieu's theoretical reflections (Heilbron 1999; Heilbron and Sapiro 2002, 2007). In our work, translation and publishing were conceptualised as strongly and directly related activities and fields; moreover, this connection came into being also out of a shared awareness that literary history, and its academic writing, had totally erased the role translation played in shaping the national literary field. Very often, we noticed literary history was built around national histories in some rather exclusive and far from satisfactory way. That was probably true for field theory too. Although Bourdieu never said that the borders of the field have to be national, his theory has been very much applied to the analysis of the national realm, without seeing the potential for a wider international reach. In my view, and this brings me back to the relationship between sociology and translation, translation is a social practice that can be studied, like literature and the arts, as such, in its own terms. It still is, and it was for me, a profession as well as a networking activity, involving a whole series of actors in the chain of producing translations: from the translator to the bookseller, via the publisher. All this happens of course according to specific mechanisms of selection, and to what one can understand as the norms of translation. Because of my background, I was familiar with Itamar Even-Zohar and Gideon Toury's theory of translation norms, which for the first time treated and studied translations as a sort of sociological object (Even-Zohar 1990; Toury 1995). At the time, though, there was no sociology of translation per se, and we have had to develop this specialism from there. I do not see translation as exclusively linked to the sociology of literature, of course, simply because one can have translations of social sciences, or all kinds of technical translations, and so on, but I do see it as a very productive synergy.

FB: How would you explain the success of Bourdieu's work in the field of translation studies from the 1990s onwards?

GS:

Translation studies as such is also a fascinating object for the history of the social sciences and the humanities. Interestingly though, while advancing more rapidly in small countries, it did not develop as much in countries such as France or the US [United States] or the UK [United Kingdom], which, having central languages, could ignore other languages, and where the multilingualism of the elite is not as established as it is in smaller countries. For example, contrary to what happens in France, the 
US, or the UK, translation studies works are very much valued in Belgium, in Israel, in the Netherlands, three small countries with a very high degree of multilingualism. In the US, translations occasionally carry the value associated with the names of prestigious translators, but usually this is not the case, since translations are even disguised as originals. This is something I discovered in my fieldwork on translation in the United States: their status is not acknowledged on their covers, because publishers are afraid that otherwise they would not sell. The perceived value of translation is very low in US culture, much more so than in France. Yet even in France the interest in translation is, at any rate, a recent phenomenon. It is only since the 1980 s that it has become greatly valued socially and, as a consequence, translators have acquired a form of status recognition, though this is still not a very high one. France's relatively late awareness of its declining position in the context of globalisation and its opening up to other cultures called for an understanding that translation is a way of strengthening its position on the international cultural scene. Returning to Bourdieu, of course field theory itself was a very helpful theoretical model for approaching translation: field, habitus, and cultural capital are three concepts that are rather central in Bourdieu's theory, and they are very helpful in thinking about translation. The sociology of publishing is also a developing area of research, taking its move from Bourdieu's last empirical work on publishing, which in fact included translation as one of its variables in order to compare publishers among themselves. He was chiefly interested in translation as a sign of symbolic orientation of a publisher's list, and not only a means of making a profit for the publisher. He understood translation as an indicator of a trajectory (Bourdieu 1999; Sapiro 2008c). Daniel Simeoni's (1998) paper about the habitus of the translator is also a case in point. He argued that focusing on the translator's habitus can shift the perspective of the theory of translation norms, because it will challenge us to try to understand the choices made by translators more closely. I wrote a paper on how you could test the issue of norms of translation from a sociological point of view (Sapiro 2008a). The specific focus was not only on cultural norms as such, but rather on differences which apply in various domains in publishing, where the norms are not universally the same: e.g. the norms for children's literature have a much greater tendency to adapt the translation to the target-culture (for instance by changing the proper names, the colour of the hair or of the eyes and so on), than in upmarket fiction or philosophy. For philosophy or upmarket literature, on the contrary, you have very high expectations relating to a norm that requires translations to be truthful to the origins of texts. This example proves that translation norms are not unified in a given culture, but depend on the field of activity to which the translated texts relate: for upmarket literature, the norm of faithfulness results from the sacralisation of the original (for 
FB:

GS: instance, a text cannot be shortened). The same thing happens with the human social sciences, translation norms are linked to the expectations of the field: a translation has to be truthful, must not make any interpretation errors (though such errors are frequent), and a text can be shortened under certain conditions but this would require an explanation from the editor (and the agreement of the author when she is alive). So the translation field is not autonomous from these specific fields.

In looking back at the origins of the connections between translation and sociology and at your own experience, you mentioned the idea of translation as a social practice, while also touching upon the polymorphous nature of translation activity itself, for it is both a literary and a social endeavour. Crucially, you have identified as distinctive of such translation activity the relationship it establishes across and from national borders towards the mapping of a broader transnational field. In order to analyse this national and transnational configuration of translation activity, do we need to engage in a sociology of translation or in a history of translation? In other words, would you subscribe to a diachronic or synchronic approach in your sociology of translation?

At the Centre Européen de Sociologie et de Science Politique, we are developing an historical sociology, which differs from the present mainstream in sociology, but which is nonetheless not exactly history per se, though it can and does use historical methods. We do not, however, conceive of it in terms of very general models, which would, therefore, be applied to every society at all times. Although there are types of oppositions, like dominant/dominated, which can be found everywhere, one always has to reconstruct the object of enquiry from an historical perspective and compare processes and systems. And especially so when analysing translation practices, which have not been considered a professionalised/standardised activity in every social context and across all centuries. Having said that, we nonetheless share some methodological tools with historians of translation. In our conceptualisation, there is indeed no clear-cut distinction between the history and sociology of translation. The main distinction one could identify is that our sociological approach focuses more on the institutions, the agents of translation, the social conditions of translation and of the circulation of books, and we are probably less interested in events as such. For instance, we can observe an evolution between the first half of the twentieth century and the second, from an international market of translations in which nation states played a major role, to a global market dominated by literary agents and large conglomerates. Yet the nation states continue to play a role, for instance through policies in support of translations. Other institutions, like UNESCO [United Nations Educational, Scientific and Cultural Organization], contributed to the globalisation of this market in 
FB:

GS:

FB:

GS: the $1950 \mathrm{~s}-1960 \mathrm{~s}$, by subsidising translations from non-Western cultures (Asian, Indian, Latin American).

As we began the interview, you did mention the notion of multiple agency, as encapsulated in the different levels of translation. The way you have been looking at the multi-layering of translation activity does indeed do justice to translation as a complex and multifaceted object of enquiry, or even as an autonomous field, within both the publishing and the literary field, but could we also see it as a network of practices, which are interconnected across national fields? Would this be an accurate assessment of your sociology of translations?

There are two different ways to use Bourdieu's concept of field when approaching translation. Two scholars very well acquainted with Bourdieu's field theory and with translation theory, Rakefet Sela-Sheffy and Jean Marc Gouanvic, claim, albeit in different ways, that there is a field of translation, organised around the competition among translators over the acquisition of recognition or symbolic capital. This is right from a professional standpoint. Yet, when you observe the market for translations, you see that it is not autonomous from the publishing field, on the one hand, and from the specific fields from which they borrow their norms (the literary field, the field of social and human sciences, and so on), on the other. Though languages compete with each other in the publishing field, they also compete with the book production in the national language.

In this sense, would you say that the competition takes place not only between languages, since translation also means competing with what is perceived as the 'official' national literature within the national publishing field. For example, if we assume that the field of publishing is made of single publishers and that all of them have a voice, would you agree that it is precisely the multiplicity of the voices articulated by translation, or by the 'foreign', that can challenge the hegemony of the national tradition? And that competition itself across the field is a transformative force? In the social sciences domain, how would you describe this competition?

I would not use that example. Publishers are competing for and across the whole publishing field. You have two uses of the concept of field: the one you are using, which is more methodological and conceptualises the oppositions inside the field; and then there is a more restrictive use of the field of theory as a field of activity, which is more or less 'autonomised'. Languages are competing with one another in the publishing industry: for instance, in book series of foreign literature published in nonanglophone countries, you will have every year, in what is a limited number of titles, one third of novels translated from English and two thirds from other languages. So, the editor has to arbitrate among peripheral languages: he or she might have to choose between a Chinese and a Korean novel. In series or in the 
lists of publishers who do not separate translations, the competition is even harsher because all the translated books compete with the books in the original language, and it often happens that most translations will be from English. The situation is even worse in dominant countries, like the United Kingdom and the United States: publishers consider translations as too expensive and not profitable enough, so they are very rare. And, it is certainly right that there was some point in history when national writers were opposed to translations because it was challenging them ... So, it is a real issue and if you miss that, if you autonomise too much the translation field from its historical context, you will miss that productive, unique tension between the national and the transnational dimension every form of cultural transposition naturally fosters.

FB:

Of course, but the publishing house will have had to form a strategy, which will promote certain translations, translators and authors over others; and this is both a way of competing with other publishers and of producing further symbolic value. The notion of antagonism can therefore be readdressed, and thus transformed, into an indispensable and all-encompassing force for shaping the profile of the field and that of the activities happening in it. One agent can antagonise the other party openly of course, but often it is rather a matter of placing symbolic capital and of positioning value, strategically. This redistribution of capital and value can happen to the extent of viewing competition not as antagonism per se between two or more forces, but as an almost 'invisible' and necessary practice of position-taking within the field.

GS:

In gaining and losing symbolic capital much depends on the circulation of models within any given field. Polysystem theory has demonstrated how linguistic as well as literary models were introduced in young cultures, like the Hebrew culture, through translations. For instance, literary models were imported from and via Russian, including the French ones, and they were used to create Hebrew literature. In this context, a national literature was largely built by importing foreign models through translation. More broadly, in many countries this was a way to constitute bodies of texts, rewritten in the new national language, even before people spoke and wrote in that same language.

FB: Every time two disciplines meet, as in the case of sociology of translation and history of translation, there are inevitably gains and losses. How can the brand of sociology you practice be compared to mainstream sociology? And why is translation a particularly good research topic for those scholars who decide to engage in this type of sociology? What is the analytical advantage in combining your sociological approach with the needs and aims of translation studies?

GS: $\quad$ First of all, you can certainly conceive of translation both as a profession and as a vocational activity or a 'calling'. But it is 
precisely the claim for its professionalization that calls for further study, since it represents in essence a statement for its recognition as a professional activity, while as a practice it was and it is still today not even necessarily paid for. Translating activities provide examples, cases, which can challenge the traditional sociology of professions, as well as models of linear development of professionalization. It is much more adequate, from a historical standpoint, to think of translation as an activity undergoing a development, which does not follow a linear trajectory, and which is not happening everywhere at the same time. We can observe cases of deprofessionalization, for instance, in the transition from the USSR [Union of Soviet Socialist Republics], where translators being civil servants were granted a high status, to the new Russian state, where they are experiencing harsh competition in the liberalised book market. This issue of professionalization patterns is one of the key aspects of studying translation that could actually renew sociology itself as a discipline (Sapiro 2014d).

FB: From what you have just said, I would conclude that your understanding of the sociology of translation challenges the linearity of history.

GS:

Yes, it certainly does, though historians are much less linear than sociologists can be. Sociologists have built a model of professionalization that is imagined as developing teleologically, with stages such as the emergence of professional associations, professional training, professional ethics, and so on. This model has already been criticised by the sociologist Andrew Abbott (1988), who argued that this development was in fact not linear and that different professions were constantly competing over the jurisdiction on a specific domain. The other way of looking at translation from a sociological standpoint is to consider it as an object of fieldwork, a location from where we can observe the international circulation of symbolic goods. This approach and understanding of translation activity represents much more accurately what we have been developing at the Centre Européen de Sociologie et de Science Politique (and before at the Centre de Sociologie Européenne). Translation offered us a different perspective from which to observe that circulation, one which had not been used as such before. That perspective encourages you to look at all the aspects of key practices, namely: the chain of importers; what people are prepared to invest in those activities; their beliefs, their hopes, their skills. For instance, in 2004 at a conference about translation and identity at Tel Aviv University I presented a paper, which discussed how people who have migrated can invest translation of profound meaning and how for them this can represent a way of keeping contact with the two cultures they belong to (Sapiro, in press). In this paper, I addressed the question of agency in translation and tried to identify typical social trajectories followed by translators, through the specific case of translation from Modern Hebrew into French. A first question is: how did you 
acquire the necessary linguistic skills to perform that activity? You can obtain them of course at home, or through independent learning, but then it depends on the linguistic training supply and on personal choices. At this point, you provoke a competition between languages: why would you choose a small peripheral language against English, for instance? I interviewed a Chinese translator for another research project and she told me she opted for French because she was not admitted in English, she was not good enough. It was a choice by default. Other people have family reasons for choosing to learn a language, but it is far from being automatic: some languages, especially those of working-class migrants, are not valued on the linguistic market (like Spanish and Portuguese in France in the 1960s, or Arabic nowadays). The question is rather: when do linguistic skills become a resource? And this, I believe, remains a key open question. To add a further variable, you can also acquire language through migration. In my work, I showed that some of the translators I was studying had migrated to Israel for Zionist reasons and then they came back. Translation was a way for them to maintain a contact with their second culture, since they were not really able to settle, to carry out their initial projects. In this case, it was a form of professional reconversion, which did also involve a process of building of the

FB: self, of giving it a meaning, and a process of identity formation. If I understand you correctly, what you are saying really problematises the relationship between translation and identity building/ shaping processes, and in this specific case also processes of social identity formation. This is a powerful connection, which can work both ways: for those who are physically migrating, but also for people who are not moving and who use translation as a form of opening out to the global sphere.

GS: Yes, but whereas in dominated cultures elites are generally multilingual, in dominant cultures, like for instance in the United States, to be interested in other cultures you need to have this 'migrant attitude', or maybe your parents were migrants. Interest in another culture is often related to the family trajectory, if we want to look at it sociologically. Family history is one of the ways in which you can acquire the linguistic skills you need, but then you need to have formal training in a language if you want to achieve professional recognition and reward. This is correct in principle, since you do not have all levels of training in all languages in all countries, and this factor restricts the available options. Yet what is valuable, what is profitable are in themselves questionable issues. Choosing a language is not entirely a rational choice: it also involves emotions, identity, cultural capital and many other motivations, which are not bounded to rational choices. The rational choice model is a dominant sociological paradigm I contest. For instance, I ask my students: have you ever tried to be a rational actor for 24 hours? You should try and let me know if it worked. In translation too, it is helpful to fight 
against this kind of rationalising model. Sociologist Max Weber proposed a much more sophisticated analytical model, which distinguishes four ideal types of actions: actions which are rational with regard to an aim; actions which are rational with regard to values; traditional action; and irrational action. The first corresponds to the rational choice model, but it is only one option among others: it could explain the actions of professional translators who are mainly interested in getting an income out of translation. The second ideal type fits the activity of many translators, as well as many artists, who conceive of their work as a labour of love, though of course you could say that they are not totally disinterested since they are expecting symbolic recognition, as Bourdieu would put it.

FB: Moving from the national scale to the bigger one, you have worked also on translation and globalisation: how do you see the link between these two spheres and how does it work?

GS:

I am really critical of the notion of globalisation, though I used it, but I used it to describe an historical phenomenon, which was labelled as such by the agents involved, and not as a concept in itself. If you pay attention to how publishing is developing in some countries, you can see that it is often fostered by the exchanges connected to translation practices. Globalisation of publishing is tightly linked to translation in so far as translation favours the circulation of a professional model of publishing and the development of national publishing fields in various countries. In 2008, I was invited to the Tunis international book fair, and I met the president of the publishers' association. He was trying to introduce the model of professional norms of translation, which is typical of the West, in a country where copyright is not necessarily respected. There was for instance a state programme for translating great works, by great thinkers. They began translating these books, but they forgot, in this state-sponsored programme, to buy the rights for the texts, so the president of the publishers' association told the person in charge in the Ministry: 'What about the rights? You cannot publish it without acquiring the rights.' The global issue here is that, indeed, translation was even laying the foundations of the national publishing field; it was used to expand and professionalise the book industry. International or intercultural exchange is not new as a phenomenon, and while its role may have intensified in some ways recently, it is not a novelty. There was a $50 \%$ increase of translations in the world from the 1980 s to 2000 (Sapiro 2008b, 2010, 2014e). This was an intensification of translation, for sure, but the notion that globalisation would favour and intensify intercultural exchange, if measured by number of interconnections between languages, appears to be false. Despite having an intensification of exchanges, there is also a concentration of translations around the English language. Translation from English rose from $45 \%$ to $59 \%$ in the world, while simultaneously a drop in translations from other languages was recorded. In the 
period associated with globalisation, some languages became more visible, especially Asian languages, like Chinese and Korean. Japanese has always been present on the translation market or at least it has been throughout the twentieth century. Chinese and Korean are developing a new profile, though their position is still very low in these exchanges, at least if compared to translations from English. The centre-periphery model used by Heilbron to describe this kind of exchange reveals that the central languages from which you have the highest number of books translated are also those which import less from other languages. For instance, translations into English represent only 3\% of the production in the UK, or in the US. The translation market is structured by power relations, and within it publishing houses are corporations, who can look for profits and use very aggressive methods to place their books in the market, including books in translation. When you try to work on it sociologically, you cannot explain everything only through these models (again, rational choice models), for instance through competition for economic profit, because you will inevitably find out that you have to account also for symbolic logics, and symbolic motivations, or even for the lack of economic interests (e.g. translating for free or publishing translations which are not profitable economically). This is where field theory is very useful to understand specific interests, which are not economic, and which are in fact autonomous from economic rationales. Such specific interests can be related to the belief in the value of literature, which underlies the very functioning of the literary field (Bourdieu 1992; Sapiro 2012). It all depends on the specificities of the field in which you are translating.

FB:

I agree. Looking only at economic reasons is not enough when trying to understand the circulation patterns of translations. The idea that there is a symbolic logic at work in the book market needs to be taken into account, and in this respect a less mainstream sociological approach could help. For example, the most prestigious way of translating (at least in some European cultural traditions) is probably the translator notebook where the translator (often a poet or author in his or her own right) makes a selection of what he or she considers the best material to offer to readers. The outcome is very personal, yet the shared assumption is that the work does have to make money, for it sits at the upper end of translation activity. Do you think that a sociological approach could help us to challenge this kind of assumption and re-evaluate translation practices across the whole spectrum of social activities?

GS: $\quad$ Of course, for some authors, translating is a way to develop their own writing. When I carried out my fieldwork on translation in the United States, I found small publishers in Brooklyn who had based their publishing houses in old factories. One of them was translating poetry from Russian and some of the poetry 
anthologies or collections they were producing were handmade. This habitus is totally opposed to the logic of the market, which is prevailing within the big conglomerates. However, even in the conglomerates you have some upmarket imprints, which are expected to be profitable. They are of course there to maintain the symbolic capital of the house, but their role cannot be only symbolic. This is a theme that was developed by Bourdieu in his theory of the field of publishing.

FB: Can you have a field without the elites or without somebody that, at some point, will occupy this space?

GS: The publishing field is an interesting field precisely because it involves the economic dimension, because it is 'business' and publishers do reconvert symbolic capital into economic capital. Bourdieu's theory discusses two logics: there is the short-term logic, which concentrates on making as much profit as possible in the shortest possible time, and then you are able to sell anything and get the money; the second choice is the long-term logic, which is not unprofitable, but is not profitable according to the rules of the market, because it can aim to be profitable in the long run, when the book becomes a classic. The rights to Camus's novel L'Etranger (1912) were sold in the US for 500 dollars after the war; in the 1960s the book became a huge bestseller because it was read in secondary schools, and as a result one million copies were sold every year. Camus was already dead by that time.

FB: These days there is much more control exercised by the publisher, situations like the one you described are less frequent because of the more careful marketing planning and the lower inclination to risk-taking.

GS: $\quad$ But you can still have a book which the writer has sold for 500 dollars. It still putatively exists because the value of that book is yet to be determined.

FB: $\quad$ The publishing world seems to be more and more aggressive in its editorial strategies, aiming to manufacture books that are likely to sell well. Surprises are rarer than in the past. There is more control on every aspect of the creative process, especially when you are marketing and selling a translation.

GS: There are always exceptions, in some way. No one can ever predict exactly what will happen once the book is in the public domain.

FB: Do you think so, still?

GS: Yes, publishers say that themselves. But John B. Thompson in his book Merchants of Culture (2010) remembers that he once arrived at a publishing house and, while he was waiting, there was a staircase there, and on it there was a sign which said 'beware of the gap', or something like that, 'please mind the gap'. He asked the secretary: 'Did so many people fall on these stairs that you had to write that?'. 'Oh no, you don't know what it means? It means that you have to fill the gap of $10 \%$ profit expected by the conglomerates, the financial shareholders.' And, if you have not 
achieved that two months before the end of the year, you have to create books to fill that gap. You just create them in two weeks, and you make sure they will sell hundreds of thousands of copies.

FB:

GS:

FB:

GS:

FB:

GS:
In other words, do you reckon that translations play an important role in this market economy? In which ways?

This is an important and difficult question. It depends on location. In the Anglo-American world, for example, while selling translation rights to other languages is a very profitable sector, translations into English are not considered as profitable. The real reason is that, in the sector of large-scale production (which is defined by Bourdieu as following the rule of short-term profit), publishers are not translating, they are just publishing in English. In all countries of the world, the pole of large-scale production is inevitably dominated by English language products, whether in translation or not. In this specific case the market sector of large-scale production translations of bestsellers, of romantic novels, of thrillers can even compete with the national production. When you come to upmarket literature things change, for you have much more diversity. Excluding some big American authors, usually national authors tend to sell better. So here you have, again, a dominant presence of Anglo-American authors, but it is much less evident, and you can also have a hard time imposing new authors, like David Foster Wallace, who took a long time to be recognised in France, for instance, though he was translated.

How would you describe the relationship between centre, periphery and locality that is challenged by translation?

Translation shows the patterns governing relations between centre and periphery very clearly, but translation also makes circulation not mechanical in a publishing field polarised between large- and small-scale circulation. Relationships between publishers and translators who belong to the world of small-scale production exist everywhere in the world, and this configuration creates a form of parallel circulation: you have the big market, the big agents, where rights are very high, but then you also have this sector of small-scale production, which is much more directly based on networking and on the symbolic capital of the person signing the deal. For example, an American small publisher will be friends with a small Italian publisher, and will trust his opinion about a potentially high quality Hungarian novel that he heard about yesterday. There is this whole kind of circulation and cooperation among the network of small publishers. As a result, linguistic diversity is much higher in the sector of small-scale production.

However, there is often another rationale at work in book circulation. You simply translate what can be acquired cheaply, and it becomes a choice, or a non-choice, for many publishers.

Yes, for instance in the social sciences and the humanities, large publishers often prefer to translate a classic work rather than a recent work, because there are no rights, the work is in the public domain, it comes free from rights. 
FB:

GS:

Or they make choices following trends and similarities in aesthetic patterns: publishers often translate what, predictably, is going to sell well, and what is cheaper to acquire. The sociology of translation, or the sociology and the history of translation (if you want to keep them separate) allow us to make an important step in this direction, for they enable us to debunk certain myths that are still kept alive about literature as a sort of purely aesthetic endeavour. When you start looking at translation from a sociological perspective, you inevitably start questioning the very shape of the text itself, together with its materiality.

In general, all publishers, even the smaller ones, ask themselves about the viability of the project, if not its profitability: can they afford to acquire the rights and to pay for the translation? Will the number of copies sold cover the costs? Very often, they will lose money, but they compensate with books that sell better. This law of compensation has been challenged by the rationalisation process: the financial shareholders expect each book to be profitable. This was why André Schiffrin (Schiffrin 2000) left Pantheon Books. There is another question that you can ask about translation: who is the author and what is the status of the translator? For instance, in the National Library catalogue in France, the translator is identified as one of the authors. And this has also become the case for the Library of Congress, but it was not like this until recently. This change has been fostered by the need to establish the social recognition of translators apart from the case of famous writers or poets whose translations become part of their work, like Baudelaire's translations of Edgar Allan Poe (1852-65); that said, there has been a prolonged discussion among professional translators, who most of the time end up denying their status as authors. The feminisation of the profession has contributed to this 'invisibility' of the translator, as Lawrence Venuti (1995) puts it, it meets expectations for femininity itself to be transparent ...

\section{References}

Abbott, A. 1988. The System of Professions: An Essay on the Division of Expert Labor. Chicago \& London: University of Chicago Press.

Bourdieu, P. 1992. The Rules of Art. Trans. S. Emanuel. Cambridge \& Stanford: Polity Press/ Stanford University Press.

Bourdieu, P. 1999. "Une révolution conservatrice dans l'édition." Actes de la recherche en sciences sociales 126/127: 3-28. English trans. 2008. "A Conservative Revolution in Publishing." Translation Studies. 1 (2): 123-153.

Even-Zohar, I. 1990. "Polysystem Studies." Poetics today 11: 1.

Heilbron, J. 1999. "Towards a Sociology of Translation: Book Translations as a Cultural World System." European Journal of Social Theory 2 (4): 429-444.

Heilbron, J., and G. Sapiro, eds. 2002. "Traduction: les échanges littéraires internationaux." Actes de la recherche en sciences sociales 144.

Heilbron, J., and G. Sapiro. 2007. "Outlines for a Sociology of Translation: Current Issues and Future Prospects." In Constructing a Sociology of Translation, edited by M. Wolf, 93-107. Amsterdam/Philadelphia: John Benjamins. 
Sapiro, G. 2008a. "Normes de traduction et contraintes sociales." In Beyond Descriptive Translation Studies. Investigations in Homage to Gideon Toury, edited by A. Pym, M. Schlesinger, and D. Simeoni, 199-208. Amsterdam \& Philadelphia: John Benjamins.

Sapiro, G. 2008b. Translatio. Le marché de la traduction en France à L'heure de la mondialisation. Paris: CNRS Editions.

Sapiro, G. 2008c. "Translation and the Field of Publishing: A Commentary on Pierre Bourdieu's 'a Conservative Revolution in Publishing' from a Translation Perspective." Translation Studies 1 (2): 2008: 154-166. doi:10.1080/14781700802113473

Sapiro, G. 2009. L'espace intellectuel en Europe. Paris: La Découverte.

Sapiro, G. 2010. "Globalization and Cultural Diversity in the Book Market: The Case of Literary Translations in the Us and in France." Poetics 38 (4): 419-439. doi:10.1016/j. poetic. 2010.05.001

Sapiro, G. 2011. La responsabilité de l'écrivain. Paris: Seuil.

Sapiro, G. 2012a. "Autonomy Revisited: The Question of Mediations and Its Methodological Implications." Paragraph 35: 30-48. doi:10.3366/para.2012.0040

Sapiro, G. 2012b. Traduire la litterature et les sciences humaines. Paris: La Documentation Francaise.

Sapiro, G. 2014a. La sociologie de la littérature. Paris: La Découverte.

Sapiro, G. 2014b. The French Writers' War, 1940-1953. Durham, NC: Duke University Press.

Sapiro, G. 2014c. Sciences humaines en traduction. Paris: Institute Francaise/CESSP.

Sapiro, G. 2014d. "The Sociology of Translation: A New Research Domain." In Companion to Translation Studies, edited by S. Berman and C. Porter, 82-94. Hoboken, NJ: Wiley-Blackwell.

Sapiro, G. ed. 2014e. "Translation and Globalization." Bibliodiversity 3; http://www.alliance-editeurs.org/translation-and-globalization-no3?lang=fr

Sapiro, G. In press. "Translation and Identity: Social Trajectories of the Translators of Hebrew Literature in French." TTR vol. 27: n. 1.

Sapiro, G., J.-Y. Mollier, H. Buzelin and A. Schiffrin. 2009. Les contradictions de la globalisation éditoriale. Paris: Nouveau Monde Editions.

Schiffrin, A. 2000. The Business of Books. NewYork, NY: Verso.

Simeoni, D. 1998. "The Pivotal Status of the Translator's Habitus." Targeting 10 (1): 1-39. doi:10.1075/target.10.1.02sim

Thompson, J. B. 2010. Merchants of Culture: The Publishing Business in the Twenty-First Century. Cambridge: Polity Press.

Toury, G. 1995. Descriptive Translation Studies and Beyond. Amsterdam \& Philadelphia: John Benjamins.

Venuti, L. 1995. The Translator's Invisibility: A History of Translation. London \& New York: Routledge.

Francesca Billiani

University of Manchester, Manchester, UK francesca.billiani@manchester.ac.uk 